\title{
Relationship among antibiotic residues and antibacterial activity of the endemic spurge honey (Euphorbia Resinifera 0. Berg) from morocco
}

\author{
Rania Benjamaa', Abdelkarim Moujanni ${ }^{1,2}$, Anass Terrab ${ }^{3}$, Rabiaa Eddoha', Maryam Benbachir ${ }^{1}$, \\ Abderrahman Moujahid', Boubker Nasser ${ }^{1}$, Sami Darkaoui ${ }^{4}$, Nadia Zyate ${ }^{4}$, Ali Talmi ${ }^{4}$, \\ Abdel Khalid Essamadi ${ }^{1 *}$
}

\begin{abstract}
${ }^{1}$ Hassan First University of Settat, Faculty of Sciences and Technologies, Laboratory of Biochemistry, Neurosciences, Natural Resources and Environment, 577, Settat, Morocco, ${ }^{2}$ National Office of Food Safety (ONSSA), Avenue Hadj Ahmed Cherkaoui, Agdal - Rabat - Maroc, ${ }^{3}$ Department of Plant Biology and Ecology, University of Seville, Ap. 1095, 41080 Sevilla, Spain, ${ }^{4}$ Division of Pharmacy and Veterinary Inputs, Control and Expertise Department, ONSSA, Rabat, Morocco
\end{abstract}

${ }^{*}$ The author to whom correspondence should be addressed

\section{A B S T R A C T}

Antibiotic-resistant bacteria continue to be of major health concern worldwide. In recent years, several reports and scientific articles claim the contamination of honey by antibiotics, detectable concentrations of antibiotic residues in honey are illegal. They, may cause hypersensitivity or resistance to drug therapy in humans, and are perceived by consumers as undesirable. In this sense, the purpose of this work was to examine the antibacterial activity of the Euphorbia resinifera (E. resinifera) honey against Escherichia coli and Staphylococcus aureus in vitro using the well-agar diffusion assay followed by dilution range to obtain more precise minimum inhibitory concentration values. The second aim is to evaluate the presence of antibiotics in honey using a screening test: Evidence Investigator ${ }^{\mathrm{TM}}$, an immuno-enzymatic method for detection of 27 antibiotic residues followed by a liquid chromatography-tandem mass spectrometry (LC-MS/MS) for confirmation of suspect samples; in order to assess the relationship between the presence of antibiotic residues and the antibacterial activity of honey. In this study, a total of $37 \mathrm{E}$. resinifera honey samples were analyzed. The results show that all samples of honey inhibited the growth of bacteria at the dilutions at $50 \%(\mathrm{v} / \mathrm{v})$; the highest inhibition zone $(25.98 \pm 0.11 \mathrm{~mm})$ was recorded from sample 5 for Staphylococcus aureus and $(13.84 \pm 1.10 \mathrm{~mm})$ in sample 17 for Escherichia coli and that $50 \%(\mathrm{v} / \mathrm{v})$ dilutions showed significant antibacterial effect compared to other dilutions $(6.25,12.5,25 \%(\mathrm{v} / \mathrm{v}))$. In all samples, there were no antibiotic residues detected except for one showing the detection of Trimethoprim at $6.48 \mu \mathrm{g} \mathrm{kg}-1$. Our research is one of the first studies that relate the he relationship between the presence of antibiotic residues and the antibacterial activity of Euphorbia resinifera honey and showed that the antibacterial activity of honey might be due to the high osmotic nature, a low pH, its content of phenolic compounds and hydrogen peroxide and also to its content of methylglyoxal.

Keywords: Euphorbia resinifera honey; antibacterial activity; antibiotic residues; multi-array; screening; LC-MS/MS

\section{INTRODUCTION}

In Morocco, the E. resinifera unifloral honey, called "Zakkoum" honey in Arabic, is very much appreciated it represents an important medicinal and ethnopharmacological resource (Ihitassen, 2019). This type of honey is produced exclusively in a principal and unique area located in the Middle Atlas (Tadla-Azilal region). The plant E. resinifera $O$. Berg, a large perennial leafless cactus-like, is an endemic species of Morocco (Chakir et al., 2016). The annual flowering of this
Euphorbiaceae is very limited between three and four weeks beginning at the end of July.

The very distinct quality of this unique honey is obtained through the leafy E. resinifera vegetation covering exclusively the mountains of the Tadla-Azilal region. This specific honey is well-known for its tasting and medicinal qualities that differentiate it from other types of Moroccan honeys. This typicity is sought by the majority of the beekeepers of Morocco who settle in the region during the flowering period of the E. resinifera. In fact, E. resinifera honey from

\footnotetext{
${ }^{*}$ Corresponding author:

Dr. Abdel Khalid Essamadi, PhD, Hassan First University of Settat, Faculty of Sciences and Technologies, Laboratory of Biochemistry, Neurosciences, Natural Resources and Environment, 577, Settat, Morocco, E-mail: essamadi@uhp.ac.ma
}

Received: 1 September 2020; $\quad$ Accepted: 29 October 2020 
the Tadla-Azilal region is the first officially honey labeled, by the Union of Beekeepers Cooperatives of Tadla-Azilal, as having protected geographical indication -PGI- in Morocco (Ministry of Agriculture and Fisheries of Morocco, 2012).

This type of honey has been the subject of several publications concerning its physicochemical composition and its color (Moujanni et al., 2018), its bacteriological quality (Moujanni et al., 2017a), antibacterial activity (Noaman et al., 2004), its anti-inflammatory capacity (Khiati et al., 2012) and identification of pesticides residues and heavy metals (Moujanni et al., 2017b).

The antimicrobial properties of honey have been investigated by a number of researchers worldwide, and It has been shown that the inhibitory activity has been attributed to osmolarity due to its high sugar content (Cooper et al., 1999), naturally low pH (Bang et al., 2003), production of hydrogen peroxide present in honey due to the action of glucose oxidase enzyme (Olaitan et al., 2007) and also the presence of phenolic acids (Estevinho et al., 2008; Biluca et al., 2016).

Even though it is strictly prohibited and no antibiotic has a marketing authorization for the treatment of bees, the antibiotics are used illegally in beekeeping, mainly tetracyclines, streptomycin, sulfonamides and chloramphenicol (Gaudin et al., 2014) for the treatment and prevention of diseases such as American and European foulbrood (Bogdanov, 2006).

The presence of antibiotic residues in honey present a risk to the health of consumers, because they could be a source of allergic reactions (Toldra and Reig, 2006) and can lead to obtaining bacterial resistant strains to antibiotics after consumption of honey (Bargańska et al., 2011). That is why, in recent years, several publications have focused on the determination of antimicrobial contaminants in beekeeping products especially honey (Kumar et al., 2020; Savarino et al., 2020).

Screening methods are the first step in controlling antibiotic residues in food (Gaudin, 2017; ANSES, 2019; AFNOR, 2014). They can detect the presence of an antibiotic or group of antibiotics at the level of interest, and usually provide qualitative results (Jakšić et al., 2018). Then, in a second step the residues of the positively tested samples are quantified mostly by quantitative confirmation methods such as using an analytical method based on high performance liquid chromatography associated with a mass detector (HPLC-MS/MS) (Gaudin, 2017; Jakšić et al., 2018; Laurentie et al., 2002; Kaufmann et al., 2002). For that reason, none of these factors taken individually seen to be enough to explain the antibacterial activity.
Detection of antibiotic residues in honey could provide interesting evidence of the close relationship between the presence of antibiotics and the antibacterial activity of honey. Therefore, there is a need to ensure that the antibacterial action of E. resinifera honey stems partly from a phytochemical component, and not from the presence of antibiotic residues used by beekeepers.

To our knowledge, no study has examined the relationship between the presence of antibiotic residues and the antibacterial activity of honey. The objective of this study is two-fold: First to determine in vitro antibacterial activity of E. resinifera honey against Staphylococcus aureus (S. aureus) and Escherichia coli (E. coli), and to second to ensure that E. resinifera honey is free from antibiotic residues using screening test: "Evidence Investigator ${ }^{\mathrm{TM}}$," is an immuno-enzymatic method for detection of 27 antibiotic residues in 37 E. resinifera honey samples. In the second level, LC MS/MS was used for confirmation of suspect samples.

\section{MATERIALS AND METHODS}

\section{Materials \\ Chemicals and reagents}

Antimicrobial Array I Ultra Kit (AM I, EV3843), Antimicrobial Array II Plus Kit (AM II, EV 4169 A/B), Antimicrobial Array III Kit (AM III, EV3695), Antimicrobial Array V (AM V, EV4027) were purchased from Randox Laboratories Ltd. 55 Diamond Road, Crumlin, County Antrim, United Kingdom. All chemicals and solvents used were of analytical grade and suitable for LC/MSMS. All references standards were from Sigma-Aldrich (Seelze, Germany). Pharmaceutical standards (chloramphenicol, semicarbazide, -1-aminohydantoïne,3-amino-2oxazolidone, -5-morpholinométhyl-3-amino-2oxazolidone, oxytetracycline, epioxytetracycline, tetracycline, epioxytetracycline, chlortetracycline, epichlortetracycline, trémethoprime, marbofloxacin, norfloxacin, ciprofloxacin, danofloxacin, enrofloxacin, sarafloxacin, difloxacin, nalidixic acid, oxolinic acid and flumequine) were purchased from Sigma-Aldrich (Seelze, Germany). The commercial antibiotics discs were from Sanofi Diagnostics Pasteur, France. Mueller Hinton agar, nutrient agar was purchased from Biocard-France and trypticase soy broth from TSB, BBL Microbiology Systems, USA.

\section{Honey samples}

Thirty-seven (37) samples of E. resinifera honey, produced by Union of beekeeping cooperatives of the Tadla-Azilal region in 2017, were purchased from the sales area in Afourer city and from the stand of this cooperative at the market of International Exhibition of Agriculture of 
Meknes (Morocco). The samples have not been heated or pasteurized. All samples were stored at $4^{\circ} \mathrm{C}$ until assay, because levels of sulfonamides in honey are known to decrease over time when the honey is stored at room temperature (Sheth et al., 1990).

\section{Microorganisms}

Microorganisms were supplied by Microbiology Laboratory of the Pharmaceutical and Veterinary Products Division of National Office of Food Safety (ONSSA) Rabat-Morocco. All bacteria were of standard strains (ATCC, US) including one gram-positive bacteria (S . aureus (ATCC 6538)) and one gram-negative bacteria (E. coli (ATCC 10536)).

\section{Preparation of honey solutions}

Solutions of honey were handled aseptically and protected from bright light to prevent from photodegradation of the glucose oxidase that gives rise to hydrogen peroxide in honey (Nair and Chanda, 2006). Dilutions (v/v) of each honey sample were made in sterile distilled water to obtain final concentrations of $6.25,12.5,25$ and $50 \%$.

\section{Antibacterial activity of honey \\ Preparation of bacterial suspensions}

The isolates were identified based on standard microbiological techniques and sub-cultured in nutrient agar slopes at $37^{\circ} \mathrm{C}$ for $24 \mathrm{~h}$. Colonies of fresh cultures of the different microorganisms from overnight growth were picked with sterile inoculating loop and suspended in $3 \mathrm{ml}$ nutrient broth contained in sterile test tubes and incubated for $3 \mathrm{~h}$ at $37^{\circ} \mathrm{C}$. This was diluted with distilled water to set inoculum density used in this study (Patton et al., 2006).

\section{Susceptibility testing of honey}

Well diffusion and Spectrophotometric assay by Chaibi et al., (1996). The antibacterial activity of the honey was tested against the gram-negative bacteria E. coli (ATCC 10536) and gram-positive $S$. aureus (ATCC 6538). The choice of $E$. coli and $S$. aureus strains is based on their parietal differences (Gram + and Gram -), the problems that they cause in a clinical setting as well as the challenge they to face with a modern anti-biotherapy especially the treatment of wounds.

The agar well diffusion technique was used to screen for antibacterial activity of honey. The well diffusion method was employed. Fresh culture suspension of the test microorganisms $(100 \mu \mathrm{l})$ was spread on Mueller Hinton agar plates.

The concentration of cultures was $1 \times 10^{7} \mathrm{CFU} \mathrm{ml}{ }^{-1}$.

The honey samples were first inoculated separately on standard nutrient media with no test organisms to evaluate their possible contamination. Thereafter, solidified nutrient agar plates were separately flooded with the liquid inoculums of the different test organisms using the pour plate method. The plates were drained and allowed to dry at $37^{\circ} \mathrm{C}$ for $30 \mathrm{~min}$ after which four equidistant wells of $5 \mathrm{~mm}$ in diameter were punched using a sterile cork borer at different sites on the plates. $10 \mu \mathrm{l}$ of the different concentrations $(6.25,12.5,25$ and $50 \%(\mathrm{v} / \mathrm{v}))$ of the honey samples were separately placed in the different punched wells with $1 \mathrm{ml}$ sterile syringe. The plates were allowed to stay for $15 \mathrm{~min}$ for pre-diffusion to take place followed by an overnight incubation that lasted for $24 \mathrm{~h}$ at $37^{\circ} \mathrm{C}$. The ZDI and the diameter of the well were recorded. Each assay was carried out in triplicate. Nutrient agar plate without honey was similarly inoculated as a control. All tests were performed in triplicate and the inhibition zones of honeys were compared with those of antibiotics used (Patton et al., 2006).

\section{Determination of Minimum Inhibitory Concentration (MIC)}

The MIC of honey was determined according to the method adopted by (Chaibi et al., 1996). The tubes containing $10 \mathrm{ml}$ of trypticase soy broth (TSB, BBL Microbiology Systems, USA) were filled by different concentrations of the honey to be tested. These tubes were aseptically inoculated with the strain to be tested at the final concentration of $3 \times 10^{6} \mathrm{CFU} \mathrm{ml}^{-1}$ and then incubated at $35^{\circ} \mathrm{C}$ for $24 \mathrm{~h}$. The optical density (OD) was determined initially in a spectrophotometer at $620 \mathrm{~nm}$ and after $24 \mathrm{~h}$ of incubation. The inhibition is expressed by the inhibition index (II) calculated according to the following formula:

$$
\mathrm{II}=1-\frac{O D 1}{O D 2}
$$

where, OD1: difference between the absorbance after $24 \mathrm{~h}$ of incubation and the absorbance at the starting time of incubation with the honey sample; OD2: difference between the absorbance after $24 \mathrm{~h}$ of incubation and the absorbance at the starting time of incubation without the honey sample. An II $=0$ indicates that there is no inhibition, $\mathrm{II}=1$ shows total inhibition, II $>1$ results in cell lysis and II $<0$ would indicate that there is growth stimulation (Chaibi et al., 1996). The readings were repeated 3 times for each concentration of honey and for the three strains tested.

\section{Antibiotic susceptibility test}

Antibiotic susceptibility for the pathogens and their reference strains were detected using the disk diffusion method, according to the standards set by the Clinical and Laboratory Standards Institute (CLSI). An aliquot of $100 \mu \mathrm{l}$ of an overnight culture was diluted in saline solution to about $1.5 \times 10^{8} \mathrm{CFU} \mathrm{ml}{ }^{-1}$ (0.5 Units of McFarland turbidity standard). 
Mueller Hinton agar plates were flooded with this suspension to give confluent colonies. The plates were then incubated at $37^{\circ} \mathrm{C}$ for $24 \mathrm{~h}$ to $48 \mathrm{~h}$ and the diameters of the clear zones around each disk were measured after incubation. The tested antibiotics were as follows: Erythromycin $(15 \mu \mathrm{g})$, Ciprofloxacine $(5 \mu \mathrm{g})$, Doxycycline $(30 \mu \mathrm{g})$, Cephalothin $(30 \mu \mathrm{g})$ and Ampicilline $(2 \mu \mathrm{g})$.

\section{Evidence Investigator ${ }^{\mathrm{TM}}$ system Antimicrobial Array kits used}

AMI is used in detecting multiple groups of antibiotics which are specifically found in honey. It, simultaneously, detects on a single honey sample: Sulfadiazine (SZ), sulphadimethoxine (SDM), sulphamethazine (SMT), sulfathiazol (ST), sulphisoxazole (SS), sulphamonomethoxine (SMM), sulphapyridine (SP), sulphamethoxypyridazine (SMP), sulphachlorpyridazine (SCP), sulphadoxine (SD), dapsone (DAPS), sulphaquinixaline (SQ), sulphamerazine (SM) and trimethoprim (TMP). AM II test is used for quinolones (QNL), ceftiofur (LSF), streptomycin (STR), tylosin (TYL) and tetracyclines (TC). AM III (EV3695) is used to detect the nitrofuran family: 3-amino-2-oxazolidinone (AOZ), 5- methylmorpholino-3-amino-2-oxazolidinone (AMOZ), 1-aminohydantoinhydrochloride (AHD) and semicarbazide (SEM) and AM V is used for the detection of chloramphenicol (CAP).

\section{Sample preparation}

AM I (EV3843), and AM II (EV 4169 A/B): A total of $1 \mathrm{~g}$ of honey sample is weighted out. Then $9 \mathrm{ml}$ of diluted wash buffer warmed to $37^{\circ} \mathrm{C}$ are added. The tubes are placed on a roller for $10 \mathrm{~min}$. The sample is now ready for application to the biochip.

AM III (EV3695): $1 \mathrm{~g}$ of honey was weighed and $4 \mathrm{~mL}$ of double denoised water warmed to $37^{\circ} \mathrm{C} .0 .5 \mathrm{ml}$ of $1 \mathrm{M} \mathrm{HCl}$ and $145 \mu \mathrm{l}$ of $10 \mathrm{mM}$ 4'Nitrobenzaldehyde were added, vortexed for $1 \mathrm{~min}$ and centrifuged for $10 \mathrm{~min}$ at $4000 \mathrm{tr}$ $\min ^{-1}$ at $25^{\circ} \mathrm{C} .3 \mathrm{ml}$ of the supper ethyl acetate layer was transferred to a clean glass test tube and dried down at $50^{\circ} \mathrm{C}$. The samples were resuspended in $1 \mathrm{ml}$ of hexane and $1 \mathrm{ml}$ of diluted wash buffer, vortexed for 2 minutes and centrifuged at $4000 \mathrm{tr} \mathrm{min}^{-1}$ for $10 \mathrm{~min} .50 \mu \mathrm{l}$ of the lower aqueous layer was used for the test of the biochips.

AM V (EV4027): $2 \mathrm{~g}$ of honey was weighed. $4 \mathrm{ml}$ of diluted wash buffer warmed to $37^{\circ} \mathrm{C}$ are added. The tubes are placed on a roller for $10 \mathrm{~min}$ or until dissolved. Then $8 \mathrm{ml}$ of acetonitrile and $1.5 \mathrm{~g}$ of sodium chloride are added, vortexed for $2 \mathrm{~min}$ and centrifuged for $10 \mathrm{~min}$ at $4000 \mathrm{tr} \mathrm{min}^{-1}$ at $25^{\circ} \mathrm{C} .2 \mathrm{ml}$ of the top layer was removed and dried down at $50^{\circ} \mathrm{C}$, sample was reconstituted with $500 \mu \mathrm{l}$ of hexane, vortexed for $2 \mathrm{~min}$ and centrifuged at

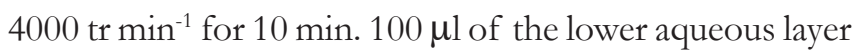
was used for the test of the biochips.

\section{Biochip analysis}

The Evidence Investigator ${ }^{\mathrm{TM}}$ Biochip Array technology is used to perform simultaneous quantitative detection of multiple analyses from a single sample. The core technology, the Randox Biochip, is supplied pre-fabricated with a panel of discrete test regions (DTRs) containing immobilized antibodies specific to different antibiotics. The biochip array assay here employs a competitive format; antibodies selective for the analyses of interest are immobilized at the DTRs. Increased levels of antibiotics in a specimen will lead to decreased binding of antibiotics labelled with horseradish peroxidase (HRP) and thus, a decrease in chemiluminescence being emitted. Detection is accomplished via imaging of a chemiluminescent signal with a CCD (charge-coupled device) camera. Each biochip contains 23 distinct test regions and unlike most current conventional immunoassay analyzers, allows multiple assays to be performed simultaneously on a single sample. The biochip assays methodology is based on standard immunoassay techniques. In most test panels, antibodies are attached to the surface of the biochip and analytes in the sample bind to them; competitive and sandwich immunoassays are used for the biochip assay and the methodology adopted is panel specific and dependent on the molecular weight of the target analytes. The concentration of analyte present in the sample was plotted and calculated from the calibration curve.

All analyses were performed according to the manufacturer's instructions. The solutions required for the test has been prepared in accordance with the suggestions of the producing company and all materials were brought to room temperature. The samples were analyzed by an Evidence Investigator AMI, AM II, AM III and AM V. $200 \mu \mathrm{l}$, $200 \mu \mathrm{l}, 150 \mu \mathrm{l}$ and $100 \mu \mathrm{l}$ of assay diluted for AM I, AM II, AM III and AM V respectively were pipetted into the wells. Next, a calibrator or sample was pipetted into the wells. To mix the reagents, all sides of the plate was tapped and the holding plate was fixed onto the bottom plate of the thermo shaker and incubated for $30 \mathrm{~min}$ at $25^{\circ} \mathrm{C}$ and $370 \mathrm{rpm} .50 \mu \mathrm{l}, 50 \mu \mathrm{l}, 100 \mu \mathrm{l}$ and $100 \mu \mathrm{l}$ of conjugate for AM I, AM II, AM III and AM V respectively per well was pipetted. It was incubated in the thermo shaker for $60 \mathrm{~min}$ at $25^{\circ} \mathrm{C}$ and $370 \mathrm{rpm}$.

The reagents were removed by sharply moving the process plate. Two rapid washing processes were immediately performed with diluted washing solution per well. The washing cycle was performed four more times. For each cycle, all sides of the process plate were tapped for about $2 \mathrm{~min}$. After the final wash $250 \mu \mathrm{l}$ of signal reagent was 
pipetted into the wells and incubated for $2 \mathrm{~min}$ in darkness and analyzed.

The imaging process was conducted within $30 \mathrm{~min}$. The results were automatically assessed in the Randox Evidence Investigator software. Evidence Investigator (Randox Laboratories Ltd., Crumlin, County Antrim, UK) identifies images by using Relative Light Units (RLU) which conducts the reading process via Charge Coupled Device (CCD) camera at a temperature of $-40^{\circ} \mathrm{C}$. Antimicrobial Array kits have been validated by the manufacturer as a result of validation studies with reference samples.

\section{Sensitivity}

The limits of detection (LOD) for the Evidence ${ }^{\mathrm{TM}}$ analytes for the honey matrix is shown in Table 1.

\section{LC-MS/MS confirmation}

The validation method was performed with a highperformance liquid chromatography apparatus (HPLC) type FLEXAR (PerkinElmer, Inc. USA) coupled to triple quadrupole type mass spectrometer: AB SCIEX QTRAP 5500 with turbo ion spray interface and Analyst software according to (Bohm et al., 2012). This internal method of the national office of food safety (ONSSA) antibiotic residues laboratory complies with the requirements of Decision 2002/657/EC concerning the performance of methods for the determination and confirmation of antibiotics residues in honey samples (European Commission, 2002) and guidance paper of Community Reference Laboratories (CRLs) (Community Reference Laboratories, 2007). All chemicals and solvents used were of analytical grade and suitable for LC/MSMS. Chromatographic conditions, nebulizer current and other conditions according to the type of antibiotic are shown in Table 2.

Stock standard solutions were prepared individually by dissolving each compound in water or methanol at concentrations in accordance with their dissolution properties (Sigma Aldrish). Thus, all QNL analytes were solubilized in water at a concentration of $1 \mathrm{mg} \mathrm{ml}^{-1}$. Whereas NF, CAP, TC and SA/TMP analytes were solubilized in methanol at concentration of $0.5 \mathrm{mg} \mathrm{ml}^{-1}$. These stock solutions were then stored at $-20^{\circ} \mathrm{C}$ in darkness until use. A $1 \mu \mathrm{g} \mathrm{ml}^{-1}$ composite standard solution was obtained by further dilution of the stock solutions with methanol. This solution was employed to build the different calibration curves and to provide quality control samples after adequate spiking experiments. Before being applied for LC analyses, all solutions were filtered by micro-filter $(4.5 \mu \mathrm{m})$.

\section{Statistical analysis}

Statistical differences between the different dilutions for each bacteria and the antibacterial effect for $50 \%$ dilution were determined by one-way ANOVA using Excel spreadsheets on Microsoft Office 2016. Differences were considered significant at $\mathrm{p}<0.05$.

\begin{tabular}{|c|c|c|c|c|c|}
\hline Antibiotics & LOD* & Positives* & $\%$ & High level*screened & LC/MSMS Confirmation \\
\hline CAP & 0.1 & 03 & 8 & 0.32 & ** \\
\hline QNL & 3 & 03 & 8 & 2.04 & - \\
\hline LSF & 2 & 0 & - & 3.44 & - \\
\hline STR & 5 & 0 & - & 0 & - \\
\hline TYL & 1 & 0 & - & 0 & - \\
\hline $\mathrm{TC}$ & 5 & 05 & 13 & 0 & - \\
\hline ST & 2.09 & 0 & - & 0.89 & - \\
\hline SS & 5 & 0 & - & 1.8 & - \\
\hline SP & 8 & 0 & - & 1.27 & - \\
\hline SMM & 20 & 0 & - & 1.29 & - \\
\hline SMP & 5 & 0 & - & 1.6 & - \\
\hline SCP & 5 & 0 & - & 3.51 & - \\
\hline DAPS & 3.5 & 0 & - & 0.08 & - \\
\hline SD & 5 & 0 & - & 2.58 & - \\
\hline TMP & 9 & 1 & 2.7 & 13.30 & 6.48 \\
\hline SZ & 5 & 0 & - & 0.80 & - \\
\hline SDM & $5-10$ & 0 & - & 5.43 & - \\
\hline $\mathrm{SQ}$ & 5 & 0 & - & 1.11 & - \\
\hline SMT & 5 & 0 & - & 3.53 & - \\
\hline SM & 5 & 0 & - & 1.71 & - \\
\hline SEM & 0.5 & 04 & 10.81 & $>22$ & - \\
\hline AHD & 0.3 & 04 & 10.81 & 0.38 & - \\
\hline $\mathrm{AOZ}$ & 0.08 & 01 & 2.7 & 0.89 & - \\
\hline AMOZ & 0.3 & 0 & - & - & - \\
\hline
\end{tabular}

${ }^{*}$ Randox kit, ${ }^{* *}<$ LOD 


\section{RESULTS AND DISCUSSION}

\section{Antibacterial effect of $E$. resinifera honey}

Antibacterial effect of various types of 37 E. resinifera honey samples at different concentrations $(6.25,12.5,25$ and $50 \%(\mathrm{v} / \mathrm{v}))$ against E. coli and $S$. aureus using agar well diffusion method was investigated. As shown in Table 3. $50 \%$ concentration showed significant antibacterial effect compared to other concentrations, $6.25,12.5$ and $25 \%$. In addition, the antibacterial effect for $50 \%$ concentration in E. coli and $S$. aureus was statistically analyzed. $S$. aureus showed significant antibacterial effect $(\mathrm{p}<0.05)$ compared to E. coli for all samples studied, except sample 13 ( $\mathrm{p}>0.05)$. In fact, highest inhibition zone of $13.84 \mathrm{~mm}$ was recorded for sample 17 against $E$. coli and $25.98 \mathrm{~mm}$ was recorded for sample 5 against $S$. aureus (Fig. 1). In Saudi Arabia honey, Ziziphus spina-christi honey showed an inhibition zone of $20.33 \mathrm{~mm}$ at concentration of $80 \%$ against $S$. aureus, while, an inhibition zone of $18.34 \mathrm{~mm}$ was found for Lavandula dentata honey at concentration of $50 \%$ against Proteus mirabilis. However, in Argentina, no antibacterial effect was found of various honey samples provided by apiarists against both E. coli and S. aureus (Basualdo, 2007) Similarly, no antibacterial effect was observed at concentration of $20 \%$ for Malaysian Melaleuca honey against S. aureus, while, concentrations of 60 and $80 \%$ showed an antibacterial effect against $S$. aureus with an inhibition zone of 8.1 and $13.7 \mathrm{~mm}$, respectively ( $\mathrm{Ng}$ and $\mathrm{Lim}, 2015)$. In our study, the inhibition zone was found to be positively linearly correlated with increasing honey concentrations, in addition, increasing honey concentrations showed a corresponding increase in the inhibitory effectiveness.

Regarding MIC, as shown in Table 4, the maximum microbial growth was observed for the concentrations 50 and $25 \%$. However, at 12.5 and $6.25 \%$, recorded inhibitions were very minimal for both $E$. coli and $S$. aureus, except for samples 11, 14, 18 and 19, which showed total inhibition on $S$. aureus at the concentration $6.25 \%$ with an inhibition index of $0.96,1.10,1.07$ and 1.00 respectively. In general, the results of the inhibition index show that the honey concentrations affect the growth of E. coli and S. aureus differently. For 50 and 25\% concentrations, the different honey samples showed a clear inhibition with an inhibition index of 0.95 in most cases as it is presented on Table 4 . The MIC for each honey is presented in Table 5 The lower MIC was recorded in sample 11, 14 and 19 against S. aureus $(6.25 \%)$ and these results are in agreement with (Dżugan et al., 2020) who found the MIC of the honeys against $S$. aureus ranges from 6.25 to $25 \%$. (Anthimidou and Mossialos, 2013) have reported that the MIC of manuka honey was determined at $6.25 \%$ against $S$. aureus and Four Greek and Cypriot honeys demonstrated a MIC at $3.125 \%$.

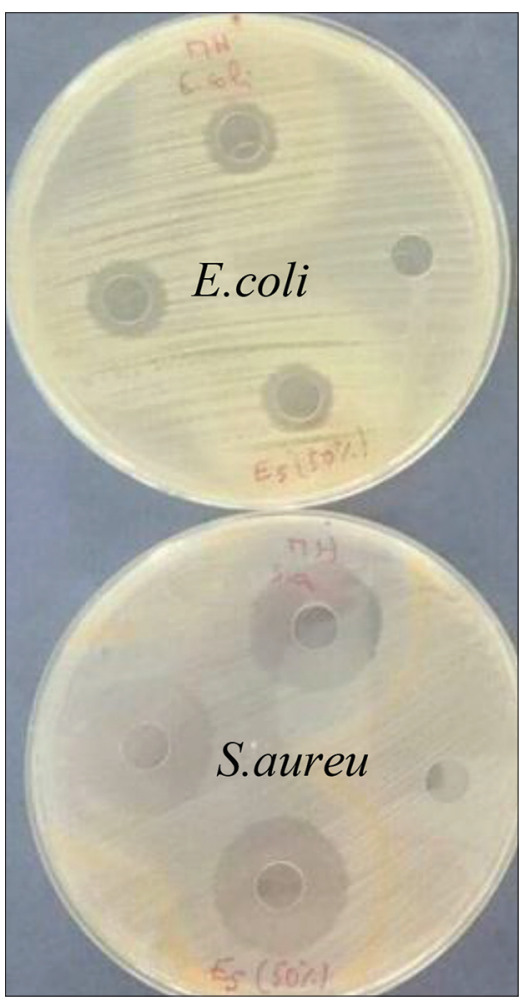

Fig 1. Inhibitory effect of honey sample 5 on $E$. coli and S. aureus at $50 \%$ concentration.

Table 2: Chromatographic conditions for analysis of different antibiotics residues by LC-MS/MS

\begin{tabular}{|c|c|c|c|c|c|}
\hline $\begin{array}{l}\text { Conditions/ } \\
\text { Antibiotics }\end{array}$ & NF & CAP & TC & TMP & QNL \\
\hline Column & $\begin{array}{l}\mathrm{C} 18-3 \mu \mathrm{m} \\
\text { particle size, } \\
150 \times 2 \mathrm{~mm}, \\
\text { pre-column, } \\
10 \times 2 \mathrm{~mm}\end{array}$ & $\begin{array}{l}\text { C18-5 } \mu \mathrm{m} \\
\text { particle size, } \\
250 \times 4 \mathrm{~mm} \text {, } \\
\text { pre-column, } \\
5 \mu \mathrm{m}, 4 \times 4 \mathrm{~mm}\end{array}$ & $\begin{array}{l}\text { C18-3.5 } \mu \mathrm{m} \\
\text { particle } \\
\text { Size, } 100 \times 2.1 \mathrm{~mm} \text {. } \\
\text { pre-column } \\
\text { C18, } 4 \times 2 \mathrm{~mm}\end{array}$ & $\begin{array}{l}\text { C18-150×3.9mm, } \\
\text { particle size } \\
5 \mu \mathrm{m}, \text { with a } \\
\text { Corresponding pre-column }\end{array}$ & $\begin{array}{l}\text { C18-150×3.9mm, } \\
\text { particle size } \\
5 \mu \mathrm{m}, \text { with a } \\
\text { corresponding pre-column }\end{array}$ \\
\hline Mobile phase & $\begin{array}{l}\text { A: Methanol } \\
\text { /2mM Ammonium } \\
\text { Formate }(1+9) \\
\text { B :Methanol } \\
\text { /2mM-Ammonium } \\
\text { Format }(9+1)\end{array}$ & $\begin{array}{l}\text { A: } \\
\text { Ammonium } \\
\text { Acetate } 0.01 \\
\text { mol.L-1 } \\
\text { B: ACN }{ }^{*}\end{array}$ & $\begin{array}{l}\text { A: PFPA }{ }^{* *} \\
0.1 \% \\
\text { B: ACN }\end{array}$ & $\begin{array}{l}\text { A: HFBA }{ }^{* \star *} \\
1 \mathrm{mM} / \text { Water } \\
\text { B: HFBA } \\
1 \mathrm{mM} / \mathrm{ACN}\end{array}$ & $\begin{array}{l}\text { A: PFPA } \\
0.1 \% \\
\text { B: CAN }\end{array}$ \\
\hline Flow & $200 \mu \mathrm{l} / \mathrm{min}$ & $10 \mu \mathrm{l} / \mathrm{min}$ & $300 \mu \mathrm{l} / \mathrm{min}$ & $350 \mu \mathrm{l} / \mathrm{min}$ & $600 \mu \mathrm{l} / \mathrm{min}$ \\
\hline
\end{tabular}

${ }^{\star}$ ACN: Acetonitril, ${ }^{* \star}$ PFPA: Pentafluoropropinoic Acid, ${ }^{* \star *} \mathrm{HFBA}:$ Heptafluorobutyric Acid 
Table 3: Antibacterial activity of Moroccan E. resinifera honey samples against S. aureus and E. Coli for different dilutions

\begin{tabular}{|c|c|c|c|c|c|c|c|c|c|}
\hline \multicolumn{10}{|c|}{ Mean diameter of inhibition zone $(\mathrm{mm})(\mathrm{n}=3)$} \\
\hline \multirow[t]{2}{*}{$\mathbf{S}$} & \multicolumn{4}{|c|}{ S. aureus (G+) } & \multirow[t]{2}{*}{$\mathbf{S}$} & \multicolumn{4}{|c|}{ E. Coli (G-) } \\
\hline & A & B & C & D & & A & B & C & D \\
\hline 01 & $17.27 \pm 0.30^{a * b *}$ & $8.40 \pm 3.50$ & 0 & 0 & 01 & $7.63 \pm 0.40^{a * b *}$ & 0 & 0 & 0 \\
\hline 02 & $16.73 \pm 0.45^{a * b *}$ & $10.95 \pm 2.18$ & 0 & 0 & 02 & $8.66 \pm 0.20^{a * b *}$ & 0 & 0 & 0 \\
\hline 03 & $10.79 \pm 2.88^{a * b *}$ & 0 & 0 & 0 & 03 & $7.54 \pm 2.56^{\mathrm{a} * \mathrm{~b} *}$ & 0 & 0 & 0 \\
\hline 04 & $16.79 \pm 1.50^{a * b *}$ & $9.18 \pm 3.50$ & 0 & 0 & 04 & $9.40 \pm 1.44^{a * b *}$ & 0 & 0 & 0 \\
\hline 05 & $25.98 \pm 0.11^{a * b *}$ & $18.83 \pm 0.23$ & $13.74 \pm 0.34$ & 0 & 05 & $9.80 \pm 0.32^{\mathrm{a} * \mathrm{~b} *}$ & $8.76 \pm 2.20$ & 0 & 0 \\
\hline 06 & $25.37 \pm 0.45^{a * b *}$ & $20.74 \pm 0.20$ & $12.35 \pm 1.20$ & 0 & 06 & $10.27 \pm 2.20^{a^{*} b^{*}}$ & $8.11 \pm 1.50$ & 0 & 0 \\
\hline 07 & $8.49 \pm 3.56^{a * b *}$ & 0 & 0 & 0 & 07 & $7.62 \pm 2.52^{a * b *}$ & 0 & 0 & 0 \\
\hline 08 & $22.36 \pm 1.77^{a * b *}$ & $17.86 \pm 2.67$ & $12.38 \pm 0.35$ & 0 & 08 & $10.98 \pm 0.96^{a * b *}$ & $8.81 \pm 0.90$ & 0 & 0 \\
\hline 09 & $9.35 \pm 5.50^{a * b *}$ & 0 & 0 & 0 & 09 & 0 & 0 & 0 & 0 \\
\hline 10 & $17.15 \pm 3.60^{a * b *}$ & $8.57 \pm 1.77$ & 0 & 0 & 10 & $9.20 \pm 2.43^{a^{\star \mathrm{b}^{* *}}}$ & 0 & 0 & 0 \\
\hline 11 & $9.82 \pm 3.54^{a * b^{*}}$ & $7.59 \pm 2.32$ & 0 & 0 & 11 & $7.98 \pm 3.76^{a * b *}$ & 0 & 0 & 0 \\
\hline 12 & $15.82 \pm 3.65^{a * b *}$ & $8.65 \pm 3.50$ & 0 & 0 & 12 & $8.98 \pm 1.34^{a * b *}$ & 0 & 0 & 0 \\
\hline 13 & $8.77 \pm 3.70^{a \star}$ & 0 & 0 & 0 & 13 & $8.34 \pm 2.45^{a \star}$ & 0 & 0 & 0 \\
\hline 14 & $16.63 \pm 3.45^{\mathrm{a} \mathrm{b} *}$ & $10.14 \pm 3.79$ & 0 & 0 & 14 & $8.86 \pm 0.40^{a * b *}$ & 0 & 0 & 0 \\
\hline 15 & $16.7 \pm 0.40^{a * b *}$ & 0 & 0 & 0 & 15 & $9.33 \pm 0.66^{a * b *}$ & 0 & 0 & 0 \\
\hline 16 & $13.86 \pm 2.90^{a * b *}$ & 0 & 0 & 0 & 16 & $9.28 \pm 2.88^{a * b *}$ & 0 & 0 & 0 \\
\hline 17 & $23.77 \pm 0.61^{a * b *}$ & $19.14 \pm 0.66$ & $11.27 \pm 1.60$ & 0 & 17 & $13.84 \pm 1.10^{a * b *}$ & $9.10 \pm 0.40$ & 0 & 0 \\
\hline 18 & $17.24 \pm 2.20^{a * b *}$ & 0 & 0 & 0 & 18 & 0 & 0 & 0 & 0 \\
\hline 19 & $14.27 \pm 3.51^{a * b *}$ & 0 & 0 & 0 & 19 & $8.95 \pm 2.00^{a * b *}$ & 0 & 0 & 0 \\
\hline 20 & $16.42 \pm 2.20^{a * b^{*}}$ & $7.71 \pm 2.96$ & 0 & 0 & 20 & $9.45 \pm 1.85^{a * b *}$ & 0 & 0 & 0 \\
\hline 21 & $12.61 \pm 3.19^{a * b *}$ & $7.54 \pm 3.40$ & 0 & 0 & 21 & $8.55 \pm 2.45^{\mathrm{a} * \mathrm{~b} *}$ & 0 & 0 & 0 \\
\hline 22 & $12.92 \pm 2.40^{a * b *}$ & 0 & 0 & 0 & 22 & $8.13 \pm 1.22^{a * b *}$ & 0 & 0 & 0 \\
\hline 23 & $17.00 \pm 0.40^{a * b *}$ & $10.06 \pm 0.78$ & 0 & 0 & 23 & $9.52 \pm 0.70^{a * b *}$ & 0 & 0 & 0 \\
\hline 24 & $18.42 \pm 3.55^{a * b *}$ & $11.47 \pm 0.45$ & 0 & 0 & 24 & $9.45 \pm 2.42^{a * b *}$ & 0 & 0 & 0 \\
\hline 25 & $17.91 \pm 2.70^{a * b *}$ & $10.23 \pm 1.17$ & 0 & 0 & 25 & $9.93 \pm 0.40^{a * b *}$ & 0 & 0 & 0 \\
\hline 26 & $14.85 \pm 3.10^{a * b *}$ & $8.87 \pm 1.90$ & 0 & 0 & 26 & $9.99 \pm 1.34^{a * b *}$ & 0 & 0 & 0 \\
\hline 27 & $14.39 \pm 2.83^{a^{\star \star b} *}$ & 0 & 0 & 0 & 27 & $7.86 \pm 3.00^{\mathrm{a} * \mathrm{~b} *}$ & 0 & 0 & 0 \\
\hline 28 & $17.35 \pm 2.50^{a * b *}$ & $11.28 \pm 3.50$ & 0 & 0 & 28 & $10.18 \pm 2.10^{a * b *}$ & $7.84 \pm 1.72$ & 0 & 0 \\
\hline 29 & $19.05 \pm 0.59^{a * b *}$ & $13.09 \pm 1.96$ & 0 & 0 & 29 & $9.77 \pm 0.44^{\mathrm{a} \star \mathrm{b} *}$ & 0 & 0 & 0 \\
\hline 30 & $14.89 \pm 3.39^{a * b *}$ & 0 & 0 & 0 & 30 & $10.58 \pm 2.19^{a * b *}$ & $8.75 \pm 2.32$ & 0 & 0 \\
\hline 31 & $10.49 \pm 2.40^{a * b *}$ & 0 & 0 & 0 & 31 & $7.31 \pm 2.90^{a * b *}$ & 0 & 0 & 0 \\
\hline 32 & $23.69 \pm 2.10^{a * b *}$ & $17.83 \pm 0.44$ & $12.54 \pm 0.77$ & 0 & 32 & $13.68 \pm 0.42^{a * b *}$ & $9.61 \pm 0.86$ & 0 & 0 \\
\hline 33 & $17.72 \pm 1.56^{a * b *}$ & $10.98 \pm 1.36$ & 0 & 0 & 33 & $9.73 \pm 1.56^{\mathrm{a} * \mathrm{~b} *}$ & 0 & 0 & 0 \\
\hline 34 & $13.95 \pm 3.78^{a * b *}$ & 0 & 0 & 0 & 34 & $8.88 \pm 3.77^{a * b *}$ & 0 & 0 & 0 \\
\hline 35 & $13.58 \pm 3.68^{a * b *}$ & $12.34 \pm 2.20$ & 0 & 0 & 35 & $10.79 \pm 1.20^{a * b *}$ & 0 & 0 & 0 \\
\hline 36 & $12.82 \pm 0.60^{a * b *}$ & 0 & 0 & 0 & 36 & 0 & 0 & 0 & 0 \\
\hline 37 & $17.55 \pm 2.12^{\mathrm{a} \star \mathrm{b} *}$ & 0 & 0 & 0 & 37 & $9.99 \pm 0.45^{a * \mathrm{~b} *}$ & 0 & 0 & 0 \\
\hline \multicolumn{10}{|c|}{ Inhibition of control antibiotics } \\
\hline AMP & $14.46 \pm 2.88$ & & & & AMP & & 0 & & \\
\hline CIP & $31.37 \pm 3.10$ & & & & CIP & $36.12 \pm 1.34$ & & & \\
\hline DO & $34.16 \pm 0.45$ & & & & DO & $23.32 \pm 3.56$ & & & \\
\hline ER & $15.34 \pm 3.05$ & & & & ER & $31.86 \pm 0.80$ & & & \\
\hline KF & $32.95 \pm 0.50$ & & & & $\mathrm{KF}$ & $9.16 \pm 3.21$ & & & \\
\hline
\end{tabular}

Results are expressed as mean \pm standard deviation, $n=3$, different letters in the table denote that the antibacterial activity studied (inhibition diameters) is influenced by the degree of dilution of the honey $\left(1 / 2,1 / 4,1 / 8\right.$ and $1 / 16$; $\left.{ }^{*} p<0.05\right)$ (letter a) and the bacterial strain (E. coli and $S$. aureus; $\left.{ }^{\star} p<0.05\right)$ (letter $\left.b\right)$.

The sensitivity of $S$. aureus and E. coli to erythromycin, ciprofloxacin, doxycycline cephalothin and ampicillin has been tested. Both strains were sensitive to antibiotics except for AMP to which E. coli was resistant Table 3. The antibacterial effect of the honey observed, in comparison with that of the antibiotics tested, shows an equivalent effect to ampicillin for $S$. aureus $(14.46 \mathrm{~mm})$ and to cephalothin for
E. coli $(9.16 \mathrm{~mm})$. Our results show, moreover, that the honey samples, diluted at $50 \%$, show an interesting inhibitory effect against $E$. Coli which is resistant to ampicillin. Coniglio et al., (2013) and Roby et al., (2020) reported that the activity of honeys can vary considerably according to the different types of flowers. Moreover, the results of our study revealed that the antibacterial activity of honeys sharing the same 
Table 4: Inhibition index for the 2 bacterial strains tested

\begin{tabular}{|c|c|c|c|c|c|c|c|c|}
\hline \multirow[t]{2}{*}{ Dilution } & \multicolumn{4}{|c|}{ S. aureus } & \multicolumn{4}{|c|}{ E. coli } \\
\hline & A & B & C & D & A & B & C & D \\
\hline Sample 01 & 1.06 & 1.09 & 0.44 & 0.09 & 1.11 & 0.84 & 0.45 & 0.38 \\
\hline Sample 02 & 1.23 & 1.14 & 0.32 & 0.06 & 1.06 & 1.04 & 0.51 & 0.15 \\
\hline Sample 03 & 0.92 & 0.98 & 1.14 & 0.38 & 1.02 & 0.75 & 0.65 & 0.34 \\
\hline Sample 04 & 1.07 & 1.12 & 0.36 & 0.1 & 1.10 & 1.10 & 0.17 & 0.16 \\
\hline Sample 05 & 1.01 & 1.03 & 0.63 & 0.08 & 1.05 & 0.88 & 0.57 & 0.56 \\
\hline Sample 06 & 1.10 & 1.11 & 0.57 & 0.53 & 1.05 & 1.03 & 0.71 & 0.75 \\
\hline Sample 07 & 1.09 & 1.09 & 0.97 & 0.16 & 1.07 & 1.04 & 0.60 & 0.72 \\
\hline Sample 08 & 1.09 & 0.35 & 0.34 & 0.07 & 1.10 & 0.20 & 0.65 & 0.39 \\
\hline Sample 09 & 1.07 & 1.03 & 0.51 & 0.27 & 1.10 & 1.00 & 0.49 & 0.35 \\
\hline Sample 10 & 1.10 & 1.04 & 0.61 & 0.50 & 1.14 & 0.99 & 0.56 & 0.21 \\
\hline Sample 11 & 1.25 & 1.02 & 0.52 & 0.96 & 1.12 & 0.92 & 0.56 & 0.21 \\
\hline Sample 12 & 1.09 & 1.11 & 0.46 & 0.62 & 1.11 & 1.11 & 0.43 & 0.09 \\
\hline Sample 13 & 1.09 & 1.04 & 0.79 & 0.32 & 1.03 & 1.00 & 0.53 & 0.35 \\
\hline Sample 14 & 1.16 & 1.06 & 0.93 & 1.10 & 0.94 & 1.02 & 0.49 & 0.23 \\
\hline Sample 15 & 1.10 & 1.09 & 0.38 & 0.53 & 1.1 & 1.09 & 0.55 & 0.34 \\
\hline Sample 16 & 1.27 & 1.14 & 0.64 & 0.62 & 1.19 & 1.09 & 0.42 & 0.11 \\
\hline Sample 17 & 1.09 & 1.04 & 0.55 & 0.16 & 1.09 & 0.71 & 0.46 & 0.44 \\
\hline Sample 18 & 1.17 & 1.09 & 1.07 & 0.87 & 0.95 & 0.93 & 0.31 & 0.32 \\
\hline Sample 19 & 1.01 & 1.01 & 0.56 & 1.00 & 1.1 & 1.09 & 0.78 & 0.61 \\
\hline Sample 20 & 1.21 & 1.12 & 0.67 & 0.92 & 1.13 & 1.09 & 0.75 & 0.72 \\
\hline Sample 21 & 1.08 & 1.04 & 0.56 & 0.13 & 1.00 & 0.87 & 0.61 & 0.36 \\
\hline Sample 22 & 1.07 & 0.90 & 0.41 & 0.44 & 1.11 & 1.00 & .032 & 0.17 \\
\hline Sample 23 & 1.04 & 1.21 & 0.62 & 0.70 & 1.08 & 1.03 & 0.43 & 0.23 \\
\hline Sample 24 & 1.13 & 1.08 & 0.65 & 0.38 & 1.13 & 1.20 & 0.43 & 0.22 \\
\hline Sample 25 & 1.20 & 1.02 & 0.65 & 0.73 & 1.05 & 0.78 & 0.60 & 0.28 \\
\hline Sample 26 & 1.10 & 1.05 & 0.54 & 0.71 & 1.12 & 0.51 & 0.53 & 0.20 \\
\hline Sample 27 & 1.03 & 1.01 & 0.55 & 0.48 & 1.00 & 0.84 & 0.74 & 0.41 \\
\hline Sample 28 & 1.07 & 1.08 & 0.59 & 0.42 & 1.16 & 0.74 & 0.65 & 0.27 \\
\hline Sample 29 & 1.04 & 1.06 & 0.29 & 0.14 & 1.02 & 1.01 & 0.61 & 0.35 \\
\hline Sample 30 & 1.08 & 1.05 & 0.35 & 0.33 & 1.1 & 0.86 & 0.49 & 0.06 \\
\hline Sample 31 & 1.05 & 1.03 & 0.64 & 0.05 & 1.02 & 0.73 & 0.59 & 0.35 \\
\hline Sample 32 & 0.98 & 0.98 & 0.3 & 0.26 & 1.02 & 0.79 & 0.53 & 0.39 \\
\hline Sample 33 & 1.02 & 1.02 & 0.54 & 0.23 & 1.04 & 0.67 & 0.65 & 0.35 \\
\hline Sample 34 & 1.08 & 0.98 & 0.43 & 0.18 & 1.1 & 0.86 & 0.49 & 0.06 \\
\hline Sample 35 & 1.2 & 1.05 & 0.44 & 0.25 & 1.16 & 1.11 & 0.37 & 0.49 \\
\hline Sample 36 & 1.03 & 0.99 & 0.18 & 0.13 & 1.05 & 0.80 & 0.30 & 0.20 \\
\hline Sample 37 & 1.12 & 1.11 & 0.7 & 0.87 & 1.1 & 0.96 & 0.71 & 0.45 \\
\hline
\end{tabular}

floral origin could differ considerably depending, on storage conditions processing and handling. Also, the gram-positive bacterial strains were the most susceptible to the effect of honey whereas the gram-negative microbes were less sensitive to all honey samples, which is in accordance with previous observations of Matzen et al., (2018), Nair and Chanda, (2006) and Khan et al., (2009). The difference in sensitivity to honey and other antibacterial agents between gram-positive and gram-negative bacteria may be due to the outer membrane of the gram-negative bacterial cell which prevents some active substances from entering the cell. Gram-positive bacteria do not have an outer membrane protecting the peptidoglycan which facilitates the penetration of antimicrobial agents and causes damage (Malanovic and Lohner, 2016).
Table 5: Minimum concentration inhibiting bacterial growth of the 2 test strains expressed in $\% \mathrm{~m} / \mathrm{v}$

\begin{tabular}{|c|c|c|}
\hline \multicolumn{3}{|c|}{ CMI (\%) qui donnant un II $\geq 0.95$} \\
\hline & S. aureus & E. coli \\
\hline Sample 01 & 25 & 50 \\
\hline Sample 02 & 25 & 50 \\
\hline Sample 03 & 12.5 & 50 \\
\hline Sample 04 & .25 & 25 \\
\hline Sample 05 & 25 & 50 \\
\hline Sample 06 & 25 & 25 \\
\hline Sample 07 & 12.5 & 25 \\
\hline Sample 08 & 50 & 50 \\
\hline Sample 09 & 25 & 25 \\
\hline Sample 10 & 25 & 25 \\
\hline Sample 11 & 6.25 & 50 \\
\hline Sample 12 & 25 & 25 \\
\hline Sample 13 & 25 & 25 \\
\hline Sample 14 & 6.25 & 25 \\
\hline Sample 15 & 25 & 25 \\
\hline Sample 16 & 25 & 25 \\
\hline Sample 17 & 25 & 50 \\
\hline Sample 18 & 12.5 & 50 \\
\hline Sample 19 & 6.25 & 25 \\
\hline Sample 20 & 25 & 25 \\
\hline Sample 21 & 25 & 50 \\
\hline Sample 22 & 50 & 25 \\
\hline Sample 23 & 25 & 25 \\
\hline Sample 24 & 25 & 25 \\
\hline Sample 25 & 25 & 50 \\
\hline Sample 26 & 25 & 50 \\
\hline Sample 27 & 25 & 50 \\
\hline Sample 28 & 25 & 50 \\
\hline Sample 29 & 25 & 25 \\
\hline Sample 30 & 25 & 50 \\
\hline Sample 31 & 25 & 50 \\
\hline Sample 32 & 25 & 50 \\
\hline Sample 33 & 25 & 50 \\
\hline Sample 34 & 25 & 50 \\
\hline Sample 35 & 25 & 25 \\
\hline Sample 36 & 25 & 50 \\
\hline Sample 37 & 25 & 25 \\
\hline
\end{tabular}

\section{Antibiotic residues}

The Evidence Investigator ${ }^{\mathrm{TM}}$ system is an adequate analytical method for screening analyses for detection of antibiotic residues in honey. It demonstrates an excellent specificity and ensures reliable results (O'Mahony et al., 2011; Popa et al., 2012; Gaudin et al., 2013, 2014, 2015).

None of 37 E. resinifera honey samples were detected with LSF, STR, TYL, AMOZ, AOZ, ST, SS, SP, SMM, SMP, SCP, DAPS, SD, SZ, SDM, SQ, SMT and SM residues. CAP and QNL were found in 3 samples (8\%), SEM and AHD were detected in 4 samples $(10.81 \%)$, TC was found in 5 samples $(13 \%)$ and TMPs and AOZ residues were found in 1 sample $(2.7 \%)$. The results obtained are shown on Table 1. 
The samples that contained antimicrobial residues were analyzed by Confirmatory analysis, here was performed via LC-MS/MS. In all samples, there were no antibiotic residues detected except for one showing the detection of TMPs at $6.48 \mu \mathrm{g} \mathrm{kg}^{-1}$ (Fig. 2). There is no fixed limit for TMPs residues neither in Morocco nor internationally (EU, Codex, FDA, etc.). Only Belgium sets a proposed recommended target concentration (PRTC) of $20 \mu \mathrm{g} \mathrm{kg}^{-1}$. The level of TMPs values detected in our study are much lower than this target. The presence of TMPs at a very low level can be explained by the contamination of honey by wax.

Indeed, since honey is produced according to a specific reference prohibiting the use of antibiotics, it is possible to emit the hypothesis that the TMPs come from an old contamination of the wax following its recycling. Their possible accumulation in wax is related to the liposolubility of TMPs.

An analysis of many bibliographic studies shows that there are antibiotic specialties for bee species in several countries of the world including the United States, Australia and Canada (Baggio et al., 2009; Barbançon et al., 2013; Codex Alimentarius Commission, 2018; Community Reference Laboratories, 2007; Food and Drug Administration, 2003; Gaudin et al., 2013, 2015; Wang, 2004; Wang et al., 2014; FAO/WHO, 2018; Zhou et al., 2009). Among the EU Member States, only Slovakia has an antibiotic with a marketing authorization for the fight against European foulbrood (Oxyoharm ${ }^{\circledR}$ containing Ox-TC) (VidalNaquet, 2015). In France, only the use of TCs is regulated by the DGAL memo of 26 April 2005. These antibiotics are listed as authorized substances of EU commission regulation $N^{\circ} 37 / 2010$ (European Commission, 2010). In Morocco, on a positive list of authorized veterinary medicines, of more than 1800 specialties, only six products are authorized for honey bees with only one antibacterial substance (Bicyclohexyl-Ammonium Fumagillin) that was approved for control of Nosema disease (National office of Food Safety, 2019).

This product has not been marketed since 2000 because of its proven genotoxicity in humans and the lack of setting of its MRL (Barbançon et al., 2013). In a study on honey, Barrasso et al., (2019) reported that 66 samples of Apulian honey tested by Evidence Investigator (AM II); TYL was detected in 38 honey samples, TCN in 36 honey samples, QNL in 9 honey samples, TAF (Thiamphenicol) in 21, LSF in 19 samples and STR was detected in 1 sample. In another study conducted by Aksem, (2019) examining a total of 45 honey samples including 5 brands of honey and 40 local honey (honey produced in the region by beekeepers) by (AM IV) test Kit; Erythromycin was detected in 41 samples (91.1\%), 10 samples $(22.2 \%)$ had STR, 8 (17.8\%) had Amikacin, 6 (13.3\%) had Lincosamides, whereas no samples were detected in spiramycin, apramycin, bacitracin, tobramycin, spectinomycin or virginiamycin antibiotic residues. On the other hand, Korkmaz et al., (2017) determined a sulfonamide and tetracycline group antibiotics in 59 natural pine honey samples collected from Aegean Region of Turkey by competitive enzymelinked immunoassay method y (ELISA); tetracycline group antibiotics were found in 35 honey samples (52.5\%) between 6 and 42 ppb while The highest amount was 42 and $38 \mathrm{ppb}$, sulfamethazine antibiotic was found in 31 honey samples (59.3\%) between 3 and 32 ppb whose the highest amount was 32 and $26 \mathrm{ppb}$.

Regarding the determination of honey antibiotics by confirmatory methods (Louppis et al., 2017) determined Thirty-six different antibiotics and residues from four different families (sulfonamides, tetracyclines, amphenicols, fluoroquinolones) and some individual antibiotics (penicillin, trimethoprim, and tiamulin) were tested in 20 commercial honey samples originating from Cyprus and Greece of different types (thyme, multifloral, pine, and orange blossom) by LC-MS/ MS, it was reported that Oxolonic acid was determined $\left(2.0 \mu \mathrm{g} \mathrm{kg}^{-1}\right)$ in one of the analyzed Greek flower honeys, sulfathiazole $\left(11.2 \mu \mathrm{g} \mathrm{kg}^{-1}\right)$ in one Cypriot thyme honey, and sulfadimethoxine $\left(17 \mu \mathrm{g} \mathrm{kg}^{-1}\right)$ in one Cypriot pine honey.

It can be seen that the differences between the results of the researchers depend on the method used in the detection of antimicrobials. Our research is one of the first studies that relate the impact of the presence of antibiotic residues on the antibacterial activity. According to our negative research regarding the results for antibiotic residues in E. resinifera honey, we can conclude that the antibacterial activity of this honey might be attributed to a high osmotic nature, a low pH (Olaitan et al., 2007) its content of phenolic compounds (Velásquez et al., 2020) and hydrogen peroxide $\left(\mathrm{H}_{2} \mathrm{O}_{2}\right)$ (Liang et al., 2020) and also to its content of methylglyoxal which is found in high concentration in Manuka honey (Atrott and Henle, 2009). Consequently, faced with these unharmonized global rules for antibiotic use in beekeeping, the Codex and consequently most countries have not laid down MRLs for antibiotic residues in honey. In addition, harmonized rules do not exist with regard to acceptable control methods, LOD or sampling methods. In some countries (e.g. Australia, Canada, India, Korea), MRLs have been set for each class of antibiotics (Community Reference Laboratories, 2007). In other countries, it was decided to establish different residues limits like action limits, recommended target concentrations, minimum required performance limit, and recommended concentration for screening and 

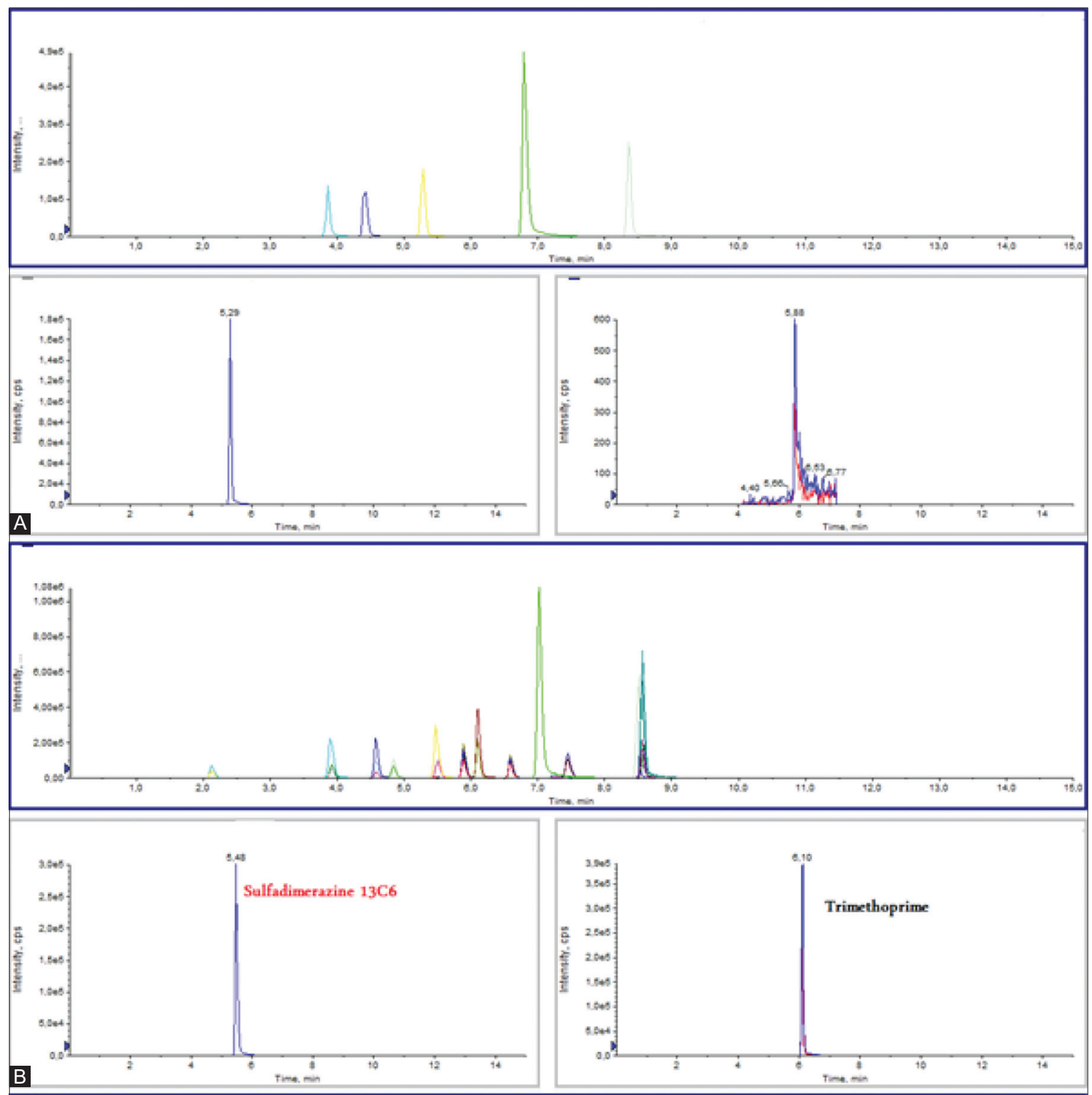

B
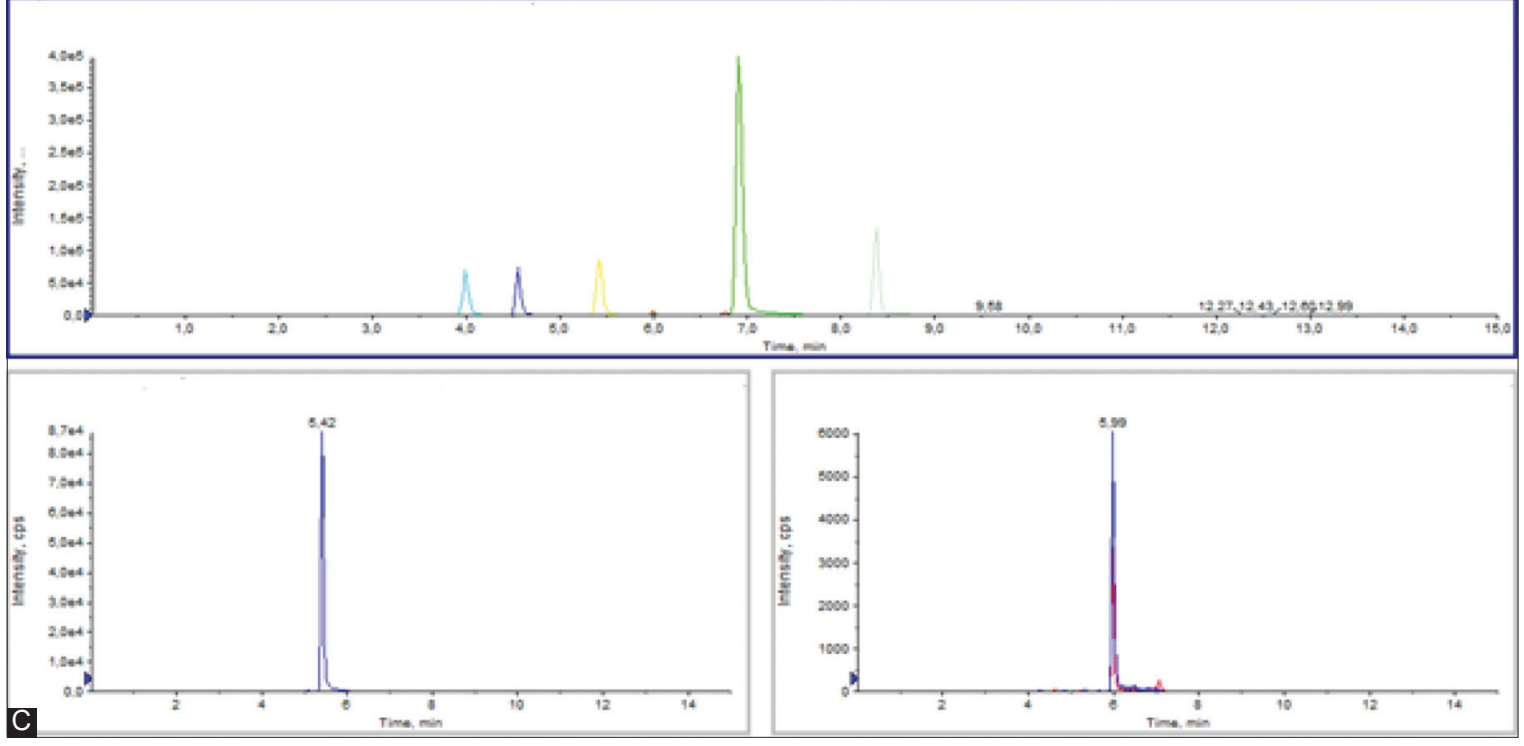

Fig 2. LC-MS/MS Chromatograms obtained for TPMs of honey sample; (A) blank sample, (B) standard and (C) suspect sample. 
non-conformity or tolerance levels (Reybroeck, 2003). Regarding the biochemistry of antibiotics in foods, they are stable in honey as parent molecules or metabolites after degradation, hence the need to look for them.

The greatest danger, in terms of human health, concerns prohibited substances, namely CAPs and NFs and, to a lesser extent, SAs. In addition, we must emphasize that, to our knowledge, this is the first published work, which deals with the important issue of antibiotic residues in Moroccan honeys.

This type of honey may be suggested for use as a natural adjunct to many diseases because of its positive health effects. Therefore, to protect the image of this kind of honey and all honey types of Moroccan origin as a healthy natural product, researchers should highlight a research program targeting Moroccan honeys labeled for their quality and benefits.

\section{CONCLUSION}

Our study demonstrates the relationship between the presence of antibiotic residues and the antibacterial activity of E. resinifera honey. According to our negative research regarding the results for antibiotic residues in E. resinifera honey, it could be concluded that the antibacterial activity of honey might be due to the honey's phytochemical characteristics, $\mathrm{pH}$, viscosity, and content of $\mathrm{H}_{2} \mathrm{O}_{2}$. The present study concluded that there is an opportunity that E. resinifera honey may be suggested according to its positive health effects, for use as a natural adjunct to many diseases whose pathogen is E. coli and S. aureus. However, further clinical studies are necessary to elucidate this hypothesis.

From a methodological point of view and through our results, we recommend that studies of the antimicrobial effects of honey can only be done after validation, of the samples studied, of the absence of antibiotic residues. It may be assessed by a rapid, simple screening method offering the detection of multiple analysts.

\section{Author contributions}

Study conception and design: A. Essamadi, A. Moujanni \& A. Terrab; Experimental work and data acquisition: R. Benjamaa, N. Zyate, A. Talmi \& S. Darkaoui; Analysis of results and bibliographic research: R. Benjamaa, A. Moujanni, \& A. Essamadi; Data interpretation: R. Benjamaa, A. Moujanni, \& A. Essamadi; Manuscript writing: R. Benjamaa \& A. Moujanni; Critical review of the manuscript: A. Essamadi, A. Moujanni, B. Nasser, R. Eddoha, M. Benbachir \& A. Moujahid

\section{REFERENCES}

AFNOR. 2014. Liste des Méthodes Utilisées Dans le Champ des Missions du Laboratoire National de Référence de l' Anses Résidus de Médicaments Vétérinaires et Colorants, pp. 3-6.

ANSES. 2019. Liste des Méthodes Utilisées dans le Champ des Missions du Laboratoire National de Référence de l'Anses, Agence Nationale de Sécurité Sanitaire de l'alimentation de L'environnement et du Travail. Résidus de Médicaments Vétérinaires et Colorants.

Aksem, A. 2019. Simultaneous screening of antibiotic residues in honey by biochip multi-array technology. Med. Weter. 75: 567-571.

Anthimidou, E. and D. Mossialos. 2013. Antibacterial activity of greek and cypriot honeys against staphylococcus aureus and pseudomonas aeruginosa in comparison to manuka honey. J. Med. Food. 16: 42-47.

Atrott, J. and T. Henle. 2009. Methylglyoxal in manuka honey correlation with antibacterial properties. Czech J. Food Sci. 27: S163-S165.

Baggio, A., A. Gallina, C. Benetti and F. Mutinelli. 2009. Residues of antibacterial drugs in honey from the italian market. Food Addit. Contam. Part B Surveill. 2: 52-58.

Bang, L. M., C. Buntting and P. Molan. 2003. The effect of dilution on the rate of hydrogen peroxide production in honey and its implications for wound healing. J. Altern. Complement. Med. 9: 267-273.

Barbançon, J. M., J. Vandame and B. Ordonneau. 2013. Evaluation de l'efficacité des médicaments de lutte contre Varroa destructor et impacts sur les protocoles de traitement. Santé Abeille. 254: 137-146.

Bargańska, Z., J. Namieśnik and M. Ślebioda. 2011. Determination of antibiotic residues in honey. TrAC Trends Anal. Chem. 30: 10351041.

Barrasso, R., E. Bonerba, A. E. Savarino, E. Ceci, G. Bozzo and G. Tantillo. 2019. Simultaneous quantitative detection of six families of antibiotics in honey using a biochip multi-array technology. Vet. Sci. 6: 1-10.

Basualdo, C. 2007. Comparison of the antibacterial activity of honey from different provenance against bacteria usually isolated from skin wounds. Vet. Microbiol. 124: 375-381.

Biluca, F. C., F. Braghini, L. V. Gonzaga, A. C. Costa and R. Fett. 2016. Physicochemical profiles, minerals and bioactive compounds of stingless bee honey (Meliponinae). J. Food Compos. Anal. 50: 61-69.

Bogdanov, S. 2006. Contaminants of bee products. Apidologie. 37: 1-18.

Bohm, D. A., C. S. Stachel and P. Gowik. 2012. Validation of a multiresidue method for the determination of several antibiotic groups in honey by LC-MS/MS. Anal. Bioanal. Chem. 403: 2943-2953.

Chaibi, A., L. H. Ababouch and F. F. Busta. 1996. Inhibition of bacterial spores and vegetative cells by glycerides. J. Food Prot. 59: 716-722.

Chakir, A., A. Romane, G. L. Marcazzan and P. Ferrazzi. 2016. Physicochemical properties of some honeys produced from different plants in Morocco. Arab. J. Chem. 9: S946-S954.

Codex Alimentarius Commission. 2018. Maximum Residue Limits (MRLs) and Risk Management Recommendations (RMRs) for Residues of Veterinary Drugs in Foods. CX/MRL 2-2018. Codex Alimentarius Commission.

Community Reference Laboratories. 2007. CRL Guidance Paper of $7^{\text {th }}$ December 2007. CRLs View on State of the Art Analytical Methods for Residue Control Plans. Community Reference Laboratories. 
Coniglio, M. A., G. Faro, G. Giammanco, S. Pignato and M. Marranzano. 2013. Antimicrobial potential of sicilian honeys against commensal escherichia coli and pathogenic Salmonella serovar infantis. J. Prev. Med. Hyg. 54: 223-226.

Cooper, R. A., P. C. Molan and K. G. Harding. 1999. Antibacterial activity of honey against strains of Staphylococcus aureus from infected wounds. J. R. Soc. Med. 92: 283-285.

Dżugan, M., D. Grabek-Lejko, S. Swacha, M. Tomczyk, S. Bednarska and I. Kapusta. 2020. Physicochemical quality parameters, antibacterial properties and cellular antioxidant activity of Polish buckwheat honey. Food Biosci. 34: 100538.

Estevinho, L., A. P. Pereira, L. Moreira, L. G. Dias, L. G. and E. Pereira. 2008. Antioxidant and antimicrobial effects of phenolic compounds extracts of Northeast Portugal honey. Food Chem. Toxicol. 46: 3774-3779.

European Commission. 2010. Commission Regulation (EU) No 37/2010 of 22 December 2009 on Pharmacologically Active Substances and their Classification Regarding Maximum Residue Limits in Foodstuffs of Animal Origin. Off. J. Eur. Communities. 15: 1.

European Commission. 2002. Commission Decision 2002/657 of 12 August 2002 Implementing Council Directive 96/23/ EC Concerning the Performance of Analytical Methods and Interpretation of Results. Off. J. Eur. Communities. 221: 9.

FAO/WHO. 2018. Maximum Residue Limits (MRLs) and Risk Management Recommendations (RMRs) For Residues of Veterinary Drugs in Foods. Codex Aliment. Int. Food Stand. 2: 2-26.

Food and Drug Administration. 2003. Tolerances for Residues of New Animal Drugs in Food. Food and Drug Administration, Washington, DC.

Gaudin, V. 2017. Advances in biosensor development for the screening of antibiotic residues in food products of animal origin a comprehensive review. Biosens. Bioelectron. 90: 363-377.

Gaudin, V., A. De Courville, C. Hedou, A. Rault, S. E. Diomandé, C. Creff-Froger and E. Verdon. 2013. Evaluation and validation of two microbiological tests for screening antibiotic residues in honey according to the European guideline for the validation of screening methods. Food Addit. Contam. Part A. 30: 234-243.

Gaudin, V., C. Hedou, C. Soumet and E. Verdon. 2015. Evaluation and validation of a biochip multi-array technology for the screening of 14 sulphonamide and trimethoprim residues in honey according to the European guideline for the validation of screening methods for veterinary medicines. Food Agric. Immunol. 26: 477-495.

Gaudin, V., C. Hedou, C. Soumet and E. Verdon. 2014. Evaluation and validation of biochip multi-array technology for the screening of six families of antibiotics in honey according to the European guideline for the validation of screening methods for residues of veterinary medicines. Food Addit. Contam. Part A Chem. Anal. Control. Expo. Risk Assess. 31: 1699-1711.

Ihitassen, A. 2019. Melissopalynology and climatic variation: Case of honey attributed to Euphorbia resinifera, Region of Azilal (Morocco). Int. J. Adv. Res. 7: 702-725.

Jakšić, S. M., R. D. Ratajac, N. B. Prica, J. B., Apić, D. B. Ljubojević, M. Z. Ž. Stošić and M. M. Ž. Baloš. 2018. Methods of determination of antibiotic residues in honey. J. Anal. Chem. 73: 317-324.

Kaufmann, A., S. Roth, B. Ryser, M. Widmer and D. Guggisberg. 2002. Quantitative LC/MS-MS determination of sulfonamides and some other antibiotics in honey. J. AOAC Int. 85: 853-860.

Khan, R., B. Islam, M. Akram, S. Shakil, A. Ahmad, S. M. Ali, M. Siddiqui and A. U. Khan. 2009. Antimicrobial activity of five herbal extracts against Multi Drug Resistant (MDR) strains of bacteria and fungus of clinical origin. Molecules. 14: 586-597.

Khiati, B., S. Bacha, M. Ahmed, S. Aissat, A. Meslem and N. Djebli. 2012. Wound care with euphorbia honey after nucleation: A case report. Clin. Microbiol. Open Access. 2: 1000129.

Korkmaz, S. D., O. Kuplulu, G. I. Cil and E. Akyuz. 2017. Detection of sulfonamide and tetracycline antibiotic residues in Turkish pine honey. Int. J. Food Prop. 20: S50-S55.

Kumar, A., J. P. S. Gill, J. S. Bedi, P. K. Chhuneja and A. Kumar. 2020. Determination of antibiotic residues in Indian honeys and assessment of potential risks to consumers. J. Apic. Res. 59: 25-34.

Laurentie, M., C. Creff-Froger and V. Gaudin. 2002. Surveillance des résidus d'antibiotiques. Apport des méthodes de spectrométrie de masse à l'identification des contaminants. Bull. Acad. Vet. Fr. 283: 61544.

Liang, Y., L. Zhang, Y. Qu, H. Li and B. Shi. 2020. Antibacterial activity of buckwheat honey added with ferrous lactate against Pseudomonas aeruginosa. LWT. 117: 108624.

Louppis, A. P., M. G. Kontominas and C. Papastephanou. 2017. Determination of antibiotic residues in honey by high-performance liquid chromatography with electronspray ionization tandem mass spectrometry. Food Anal. Methods. 10: 3385-3397.

Malanovic, N. and K. Lohner. 2016. Antimicrobial peptides targeting Gram-positive bacteria. Pharmaceuticals. 9: 59.

Matzen, R. D., J. Z. Leth-Espensen, T. Jansson, D. S. Nielsen, M. N. Lund and S. Matzen. 2018. The antibacterial effect in vitro of honey derived from various danish flora. Dermatol. Res. Pract. 2018: 1-10.

Ministry of Agriculture and Fisheries of Morocco. 2012. Euphorbia Honey of "Tadla-Azilal" and Homologation of its Specifications. Ministry of Agriculture and Fisheries of Morocco, Morocco, p. 2524.

Moujanni, A., L. Partida, A. K. Essamadi, D. Hernanz, F. J. Heredia and A. Terrab. 2018a. Physicochemical characterization of unique unifloral honey: Euphorbia resinifera. CyTA J. Food. 16: 27-35.

Moujanni, A., A. Terrab, R. Eddoha, B. Nasser, M. Benbachir, N. E. Chaouqy, T. Bouzid and A. K. Essamadi. 2017b. Microbiological quality of moroccan labeled Euphorbia resinifera honey. J. Microbiol. Biotechnol. Food Sci. 6: 1188-1194.

Moujanni, A., A. Terrab, R. Eddoha, B. Nasser, M. Benbachir, M. Tannaoui, A. Zouaoui, and A. K. Essamadi. 2017. Quantification of heavy metals and pesticides residues in labeled Moroccan Euphorbia resinifera honey from Tadla-Azilal. J. Mater. Environ. Sci. 8: 1826-1836.

Nair, R and S. Chanda. 2006. Activity of some medicinal plants against certain pathogenic bacterial strains. Indian J. Pharmacol. 38: 142-144.

National Office of Food Safety. 2019. Positive List of Veterinary Drugs Authorized in Morocco. National Office of Food Safety, Morocco.

Ng, W. J. and M. S. Lim. 2015. Anti-staphylococcal activity of Melaleuca honey. Southeast Asian J. Trop. Med. Public Health. 46: 472-479.

Noaman, M., M. Faid and C. El-Adlouni. 2004. Antimicrobial activities of natural honey from aromatic and medicinal plants on antibioresistant strains of bacteria. Int. J. Agric. Biol. 6: 289-293.

O'Mahony, J., M. Moloney, R. I. McConnell, E. O. Benchikh, P. Lowry, A. Furey and M. Danaher. 2011. Simultaneous detection of four nitrofuran metabolites in honey using a multiplexing biochip screening assay. Biosens. Bioelectron. 26: 4076-4081.

Olaitan, P. B., O. E. Adeleke and I. O. Ola. 2007. Honey: A reservoir for microorganisms and an inhibitory agent for microbes. Afr 
Health Sci. 7: 159-165.

Patton, T., J. Barrett, J. Brennan and N. Moran. 2006. Use of a spectrophotometric bioassay for determination of microbial sensitivity to manuka honey. J. Microbiol. Methods. 64: 84-95.

Popa, I. D., E. C. Schiriac and R. Cuciureanu. 2012. Multi-analytic detection of antibiotic residues in honey using a multiplexing biochip assay. Rev. Med. Chir. Soc. Med. Nat. lasi. 116: 324-329.

Reybroeck, W. 2003. Residues of antibiotics and sulphonamides in honey on the Belgian market. Apiacta. 38: 23-30.

Roby, M. H. H., Y. F. Abdelaliem, A. H. M. Esmail, A. A. A. Mohdaly and M. F. Ramadan. 2020. Evaluation of Egyptian honeys and their floral origins: Phenolic compounds, antioxidant activities, and antimicrobial characteristics. Environ. Sci. Pollut. Res. 27: 20748-20756.

Savarino, A. E., V. Terio, R. Barrasso, E. Ceci, S. Panseri, L. M. Chiesa and E. Bonerba. 2020. Occurrence of antibiotic residues in Apulian honey: Potential risk of environmental pollution by antibiotics. Ital. J. Food Saf. 9: 8678.

Sheth, H. B., M. E. Stiles, P. Sporns, V. A. Yaylayan and N. H. Low. 1990. Reaction of reducing sugars with sulfathiazole and importance of this reaction to sulfonamide residue analysis using chromatographic, colorimetric, microbiological, or ELISA methods. J. Agric. Food Chem. 38: 1125-1130.

Toldra, F. and M. Reig. 2006. Methods for rapid detection of chemical and veterinary drug residues in animal foods. Trends Food Sci. Technol. 17: 482-489.

Velásquez, P., G. Montenegro, F. Leyton, L. Ascar, O. Ramirez and A. Giordano. 2020. Bioactive compounds and antibacterial properties of monofloral Ulmo honey. CYTA J. Food. 18: 11-19.

Vidal-Naquet, N. A. L. 2015. Honeybee Veterinary Medicine: Apis mellifera L. 5M Publishing, Sheffield, United Kingdom.

Wang, J. 2004. Determination of five macrolide antibiotic residues in honey by LC-ESI-MS and LC-ESI-MS/MS. J. Agric. Food Chem. 52: 171-181.

Wang, S., W. Yong, J. Liu, L. Zhang, Q. Chen and Y. Dong. 2014. Development of an indirect competitive assay-based aptasensor for highly sensitive detection of tetracycline residue in honey. Biosens. Bioelectron. 57: 192-198.

Zhou, J., X. Xue, F. Chen, J. Zhang, Y. Li, L. Wu, L. Chen and J. Zhao. 2009. Simultaneous determination of seven fluoroquinolones in royal jelly by ultrasonicassisted extraction and liquid chromatography with fluorescence detection. J. Sep. Sci. 32: 955-964. 